\title{
An In Vitro and In Vivo Cholinesterase Inhibitory Activity of Pistacia khinjuk and Allium sativum Essential Oils
}

\author{
Peyman Ghajarbeygi', Ashraf Hajhoseini', Motahare-Sadat Hosseini ${ }^{2}$, Anoosheh \\ Sharifan ${ }^{3 *}$ \\ ${ }^{1}$ Health Products Safety Research Center, Qazvin University of Medical Sciences, Qazvin, Iran \\ 2 Biomaterials Group, Department of Biomedical Engineering. Amirkabir University of Technology, Tehran, Iran \\ ${ }^{3}$ Department of Food Science and Technology, Science and Research Branch, Islamic Azad University, Tehran, Iran
}

\section{Key Words}

alzheimer disease, cholinesterase inhibitor, phenols, wistar rats

\begin{abstract}
Objectives: Alzheimer's disease (AD), an overwhelming neurodegenerative disease, has deleterious effects on the brain that consequently causes memory loss and language impairment. This study was intended to investigate the neuroprotective activity of the two essential oils (EOs) from Iranian Pistacia khinjuk (PK) leaves and Allium sativum (AS) cloves against $\beta$-Amyloid 25-35 (A $\beta 25-35)$ induced elevation of cholinesterase enzymes in $\mathrm{AD}$.

Methods: The EOs of PK (PKEO) and AS (ASEO) were prepared and analyzed in terms of extraction yield, phenolic content, and cholinergic markers in vitro. Moreover, both were administered orally to adult male Wistar rats at concentrations of 1,2 , and $3 \%$. The inhibitory potential of PKEO and ASEO was compared with Donepezil $(0.75 \mathrm{mg} / \mathrm{kg})$ against the high activities of acetylcholinesterase (AChE) and butyrylcholinesterase (BChE) enzymes.
\end{abstract}

Results: PKEO reached an inhibition rate of $83.6 \%$ and

Received: Mar 14, 2019 Reviewed: Jun 12, 2019 Accepted: Nov 26, 2019

(c) This is an Open-Access article distributed under the terms of the Creative Common Attribution Non-Commercial License (http://creativecommons.org/licenses/by-nc/4.0/) which permits unrestricted noncommercial use, distribution, and reproduction in any medium, provided the original work is properly cited.

(2) This paper meets the requirements of KS X ISO 9706, ISO 9706-1994 and ANSI/NISO Z39.48-1992 (Permanence of Paper).
81.4\% against AChE and BChE, respectively. ASEO had lower anti-cholinesterase activity $(65.4 \%$ and $31.5 \%$ for the inhibition AChE and BChE). PKEO was found to have more phenolic content than ASEO. A significantly positive correlation was observed between the total phenolics and anti-cholinesterase potential. In rats, both EOs decreased the enzyme activity in a concentration-dependent manner. As compared with Donepezil, the significant difference in the AChE and BChE inhibition occurred as rats were treated with PKEO 3\% $(\mathrm{p}<0.05)$.

Conclusion: It could be concluded that PKEO and ASEO are potent inhibitors of AChE and BChE in rats that hold promise to be used for the treatment of AD.

\section{Introduction}

Alzheimer's disease (AD), a chronic and progressive degenerative disease, is considered as one of the most common causes of dementia in elderly [1]. Bartus et al. suggested that the cholinergic dysfunction in the brain of healthy elderly and dementia people can cause the memory loss and subsequent cognitive damage, thus, the repair of cholinergic activity probably decreases the serious lack of cognitive function [2]. Acetylcholine (ACh) is a critical neurotransmitter used by cholinergic neurons in main physiological processes, including attention, learning, memory, and so forth [3]. The presence of impairment to the cholin-

"Corresponding Author

Anoosheh Sharifan. Department of Food Science and Technology, Science and Research Branch, Islamic Azad University, 1477893855, Tehran, Iran.

Tel: +98- 912-617-8388

E-mail: sharyfana@gmail.com 
ergic pathways in the brain has attracted much attention to drug development [4]. Almost all FDA approved drugs consist of acetylcholinesterase (AChE) inhibitors [5] and their effectiveness is attributed to the extent of inhibition of cholinesterase [6]. However, because of serious side effects, such as dizziness, headache, constipation, hepatotoxicity, nausea, diarrhea, and bioavailability complications, these drugs (e.g., tacrine, donepezil and galantamine) are rarely prescribed [7]. Limitation of the available methods emphasizes the importance of natural products containing antioxidant and flavonoid compounds $[8,9]$. Essential oils (EOs) are a highly complex mixture of naturally occurring volatile compounds produced by plants in the form of secondary metabolites, and usually extracted by hydro-distillation and cold pressing methods [10]. Many research efforts have been made concerning the cholinesterase inhibition potentials of EOs [11, 12].

Allium sativum (AS, English: Garlic) has been found to have protective effects on learning deficits in mice [13] and to enhance visual memory and attention in healthy human volunteers [14]. Moreover, dietary garlic has shown to elevate the cerebral levels of $\beta$-amyloid precursor protein and $\beta$-amyloid peptide (sAPPa, sA $\beta 40, \mathrm{sA} \beta 42$ ) [15]. More recently, it has been shown that AS extract using $\mathrm{n}$-Hexane, ethyl acetate, and methanol served to protect the brain owing to high antioxidant phytochemicals and properties of female rats from oxidative stress caused by deltamethrin via attenuating AChE [16]. On the other hand, of the genus Pistacia L. (Anacardiaceae), three species are indigenous to Iran. Recently, it has been reported that the EO of Pistacia khinjuk (PK, Persian: Khinjuk), a wild pistachio with edible and medicinal applications, presents antioxidant activities [17]. This feature is postulated to account for its potential against $\mathrm{AD}$ [18]. The ethanol and ethanol-water extracts of the P. terebinthus fruits and PK seeds were observed to strongly inhibit the activities of AChE and butyrylcholinesterase (BChE) [19]. Although there is no report on the effectiveness of PK for $\mathrm{AD}$, some evidence has indicated the promising pharmacological activity of the genus Pistacia L. in AD [19, 20].

Since Iranian AS and PK have not yet been reported for neuroprotective activity despite their broad chemical constituents, the aim of this study is to investigate the inhibition of cholinesterase activity by the EOs obtained from the aerial parts of PK and cloves of AS in both in vitro and in vivo settings. To the best of our knowledge, this is the first study concerning the anti-cholinesterase activity of the EOs from the PK leaves (PKEO) and AS cloves (ASEO).

\section{Methods}

\subsection{Preparation of Eos}

Both plants were purchased from local grocery stores in Tehran, Iran (Geographic coordinate: latitude $35^{\circ} 40^{\prime} 45.5^{\prime \prime} \mathrm{N}$ and longitude $\left.51^{\circ} 24^{\prime} 02.1^{\prime \prime E}\right)$. But only PK origin was from the slopes of the Zagros, Dallahou, Iran (Geographic coordinate: latitude $34^{\circ} 20^{\prime} 23.3^{\prime \prime} \mathrm{N}$ and longitude $\left.46^{\circ} 25^{\prime} 23.4 " \mathrm{E}\right)$. They were compared with those species in the Medical Plant Farm, Jahad Daneshgah, Islamic Republic of Iran. Their names have been checked with www. theplantlist.org. The aerial parts of PK and cloves of AS from a single bulb were utilized for the extraction, which was conducted by using hydro-distillation with clevenger apparatus, Electro Mantle model. The final EOs then kept in sealed dark vials at $4^{\circ} \mathrm{C}$.

\subsection{Selection criteria and outcome assess- ment}

Gas chromatography-mass spectrometry Analysis. The resultant EOs were tested by a gas chromatograph (Agilent Technologies, Wilmington, USA) along with a mass spectrophotometer (Agilent Technologies, Wilmington, USA). An HP-5Ms capillary column $(30.0 \mathrm{~m} \times 0.25 \mathrm{~mm} \times 0.25 \mu \mathrm{m})$ was utilized for separation. The initial temperature was $50^{\circ} \mathrm{C}$ maintained for $2 \mathrm{~min}$ and then increased to $200^{\circ} \mathrm{C}$ at a rate of $3.5^{\circ} \mathrm{C} / \mathrm{min}$. After a two-min stopping at $200^{\circ} \mathrm{C}$, it afterwards increased to $280^{\circ} \mathrm{C}$ in steps of $7^{\circ} \mathrm{C} / \mathrm{min}$.

Determination of phenolic content. The Folin-Ciocalteu reagent assay was performed to determine the total phenolic content as mg gallic acid equivalents per EOs gram [17]. Briefly, a mixture of $2 \mathrm{~N}$ Folin-Ciocalteu reagent and $0.5 \mathrm{~mL}$ EOs was prepared. Following $5 \mathrm{~min}, 2 \mathrm{~mL}$ of $75 \mathrm{~g} / \mathrm{L}$ sodium carbonate was added to the solution. Thereafter, absorbance was recorded at $760 \mathrm{~nm}$.

\subsection{Animals}

Healthy adult male Wistar rats weighting 300-400 g were provided by the Razi Vaccine and Serum Research Institute. Fifty six rats were randomly assigned into eight groups and then kept separately in laboratory animal room under the standard conditions at $22 \pm 2^{\circ} \mathrm{C}$ and $12-14$ hour light (indoor lighting intensity 100 foot-candles). Humidity should be kept within a range of $30-70 \%$. The rats were given the standard diet and water ad libitum. They were also allowed to acclimate to the laboratory conditions for a week before commencement of the study. Experiments were conducted according to local guidelines for the care of laboratory animals of Science and Research Branch, Islamic Azad University, Tehran, Iran. Group 1 was treated with the intra Cerebro Ventricular (ICV) injection of A 325 35 peptide (10 $\mu \mathrm{g} / \mathrm{rat}$ ) (Sigma Aldrich, USA). Group 2 was treated with the ICV injection of $A \beta_{25-35}$ peptide $(10 \mu \mathrm{L})$ and then the oral administration (p.o.) of Donepezil ( 0.75 $\mathrm{mg} / \mathrm{kg}$ ) (positive control). Groups 3, 4, and 5 were treated with the ICV injection of $A \beta_{25-35}$ peptide $(10 \mu \mathrm{L})$ and then respectively treated with $\mathrm{PK} 1,2$, and $3 \% \mathrm{wt} / \mathrm{wt}$ (p.o.). Groups 6, 7, and 8 were treated with the ICV injection of $\mathrm{A} \beta_{25-35}$ peptide $(10 \mu \mathrm{L})$ and then respectively treated with AS 1, 2, and 3\% wt/wt (p.o.). Amnesia was induced by the ICV injection of $A \beta_{25-35}$ peptide on week 2 following exposure to PK or AS and remained for three weeks. 


\subsection{Cholinesterase inhibition}

In vitro. Enzyme inhibitory activity was determined applying Ellman's method [21]. Briefly, a total of $50 \mu \mathrm{L}$ of the EO solution was mixed with 5,5'-dithio-bis-2-nitrobenzoate (DTNB, purity 99\%), solution $(125 \mu \mathrm{L})$, and AChE or BChE solution $(25 \mu \mathrm{L})$ in Tris-HCl buffer at $\mathrm{pH}$ value of 8.0. The final solution was incubated for $15 \mathrm{~min}$ at $25^{\circ} \mathrm{C}$. With the addition of acetylthiocholine iodide or butyrylthiocholine chloride, the reaction was started. The absorbance was read at $405 \mathrm{~nm}$ after $10 \mathrm{~min}$ incubation at ambient temperature. The anti-cholinesterase activity was described as the percentage of inhibition. Donepezil was used as standard drug.

In vivo. The rats were decapitated, and then their brains were rapidly removed and transferred into ice-cold saline. Thereafter, frontal cortex, hippocampus, and septum were cut up as rapidly as possible in an ice bath. These tissues were weighed and poured into tubes containing $0.1 \mathrm{M}$ PBS ( $\mathrm{pH}$ 8) for homogenization. Subsequently, $0.4 \mathrm{~mL}$ of the homogenate was completely mixed within a cuvette containing $2.6 \mathrm{~mL}$ of PBS and $100 \mu \mathrm{L}$ of DTNB through bubbling air to measure absorbance at $412 \mathrm{~nm}$ by a spectrophotometer. Afterwards, $20 \mu \mathrm{L}$ of acetylthiocholine iodide or butyrylthiocholine chloride was added and next changes in absorbance were documented [22].

\subsection{Statistical Analysis}

All measurements were performed in three replicates. Data was described as mean \pm standard deviation (SD). The Kolmogorov-Smirnov tests were performed to ensure data normal distribution. Considering normal distribution, Pearson correlation coefficient, one-way ANOVA and Duncan's multiple range tests were initially conducted to determine any significant difference at P-values < 0.05 (SPSS 19.0 software Package, IBM Inc., Chicago IL, USA). If normal distribution evaded, non-parametric equivalents were used.

\section{Results and Discussion}

In the present study, the two plants extensively used for both cooking and medicinal purposes among Iranian were investigated for anti-cholinesterase activity in vitro and in vivo. There have been various pharmaceutical and biological applications for garlic mainly due to its anti-oxidative features that culminate in protective effects against oxidative damage as well as reductions in the risk of biomolecular impairment. These beneficial outcomes can also prevent the onset and progression of brain aging and neurodegenerative diseases to varying extent [23, 24]. In mice, it has been reported that aged garlic extract restore atrophic changes in the frontal brain, increase learning abilities and memory retention, and augment longevity in an accelerated senescence process $[25,26]$. When it comes to PK, evidence has been shown its suitability for edible and medicinal applications [19, 27]. Moreover, it was found with the significant potential to induce inhibition of fungal and bacterial strains [28]. Despite considerable improvements in $\mathrm{AD}$ symptoms upon the administration of several cholinesterase inhibitors, including tacrine, rivastigmine, and donepezil, the undesirable outcomes associated with these medications have become increasingly noticeable $[29,30]$. Thus, plant-based new drug discovery has garnered a great deal of attention and should identify the candidates with dual function and lesser negative effects for $\mathrm{AD}$ patients [9].

The extraction yield and phenolic content were $2.2 \% \mathrm{vol} /$ wt and 50.5 $\pm 1.1 \mathrm{mg}$ GAEs/g extract for PKEO and $0.1 \% \mathrm{vol} /$ wt and $258.6 \pm 4.3 \mathrm{mg}$ GAEs/g extract for ASEO. As shown in Table 2, the major three constituents of PKEO were phellandrene (53.14\%), $\alpha$-Pinene (15.58\%), and octadecanoic acid $(6.04 \%)$. There have been three published data about PKEO. Abolghasemi et al. prepared the EO from PK leaves collected from an orchard in Rafsanjan, Iran (Geographic coordinate: latitude $30^{\circ} 25^{\prime} 29.0^{\prime \prime} \mathrm{N}$ and longitude $\left.56^{\circ} 00^{\prime} 12.8^{\prime \prime E}\right)$. They identified 40 compounds out of 48 total compounds in PKEO, with myrcene (18.7\%), $\alpha$-eudesmol (12.3\%), $\beta$-eudesmol (9.3\%), 1,7-di-epi- $\beta$-cedrene (7.3\%), bicyclogermacrene (5.6\%) and $\delta$-eudesmol (4.9\%) being major constituents [31]. Their documented PKEO composition was different from ours. Moreover, the mean yield was $1.82 \pm 0.12 \mathrm{mg} / \mathrm{kg}$ dry mass in their study [31], which was slightly lower from our result. Likewise, Ghasemi Pirbalouti and Aghaee reported consistent results (phellandrene $52.33 \%$, $\alpha$-Pinene $\mathbf{1 5 . 2 8 \%}$ and $\Delta$-limonene $5.08 \%$ ) [27], whereas a completely different composition was determined by Taran et al. (Spathulenol $20.87 \%$, Germacrene B 9.53\% and Aromadendrone<dehydro > 8.80\%) [32]. Such disparities could be related to the collection time, environmental conditions, geographic locations, and extraction method employed in these studies [32, 33]. Several studies have also revealed the presence of phenolic constituents in P. khinjuk [17, 32]. Phenolic compounds in plants are responsible for a range of antibacterial, antioxidant, or free radicals scavenger properties [34].

On the other hand, ASEO in the present study mainly consisted of the three components of diallyl trisulfide (23.03\%), diallyl disulfide $(10.11 \%)$, and allyl methyl trisulfide (8.67\%) (Table 2). Owing to the lack of published data on the EO from AS cloves, it is impossible to compare the ASEO composition with other findings from different Iran regions. The extraction yield of ASEO in this study was virtually comparable to that reported by Khadri et al. (0.09\%) [35]. Nonetheless, this yield represents one fourth of the yield calculated in the study by Lawrence and Lawrence $(0.4 \%)$ [36]. Our findings on the chemical profile of ASEO was relatively similar to that documented by Mnayer et al. [37], whose study, however, showed diallyl disulfide (37.90\%), diallyl trisulfide (28.06\%), and allyl methyl trisulfide (7.26\%) as the three major constituents. Khadri et al. [35] found that allyl methyl trisulfide (34.61\%), diallyl disulfide (31.65\%), and allyl methyl disulfide $(9.27 \%)$ were rather the main compounds of ASEO. There are still other reports indicating diallyl disulfide and diallyl trisulfide as the two major constituents of ASEO $[38,39]$. There has been no study available that reported the total phenol content of ASEO. The previous work by 
Table 1 Extraction yield and total phenolic content of PKEO and ASEO (mean \pm SD)

\begin{tabular}{ccc}
\hline Samples & $\begin{array}{c}\text { Extraction yield } \\
(\%)\end{array}$ & $\begin{array}{c}\text { Total phenol content }(\mathrm{mg} \\
\text { GAEs/g extract) }\end{array}$ \\
\hline ASEO & 0.1 & $258.6 \pm 4.3^{\mathrm{a}}$ \\
PKEO & 2.2 & $50.5 \pm 1.1^{\mathrm{b}}$
\end{tabular}

Table 2 Chemical compositions of PKEO and ASEO in percent

\begin{tabular}{|c|c|c|c|c|}
\hline No & Compound & $(\%)(w / w)$ & Compound & $(\%)(w / w)$ \\
\hline & PKEO & & ASEO & \\
\hline 1 & $\alpha$-pinene & 15.58 & Methyl 2-propanol disulfide & 2.86 \\
\hline 2 & Sabinene & 0.8 & Dimethyl trisulfide & 1.32 \\
\hline 3 & Phellandrene & 53.14 & Allyl methyl disulfide & 7.00 \\
\hline 4 & $\Delta$-limonene & 4.56 & 2-Ethylidene[1,3]ditiane & 2.54 \\
\hline 5 & 1,3,6-octatriene & 1.50 & Diallyl disulfide & 10.11 \\
\hline 6 & $\gamma$-terpinene & 1.30 & Allyl methyl trisulfide & 8.67 \\
\hline 7 & $\alpha$-terpinolene & 1.02 & 3-Vinyl-1,2-ditiocyclohex-5-ene & 6.43 \\
\hline 8 & (Z)-4,8-dimetyl-1,3,7 nonatriene & 1.43 & Di-2-propenyl trisulfide (isomer) & $<0.02$ \\
\hline 9 & L-linalool & 1.69 & Diallyl trisulfide & 23.03 \\
\hline 10 & Thujopsene & 1.40 & Diallyl tetrasulfide & 6.91 \\
\hline 11 & Caryophyllene oxide & 1.65 & Benzeneacetaldehyde & 5.62 \\
\hline 12 & Hexadecanoic acid & 1.10 & - & - \\
\hline 13 & Octadecanoic acid & 6.04 & - & - \\
\hline 14 & 9-Octadecanoic acid & 1.21 & - & - \\
\hline 15 & Ethyl oleate & 1.37 & - & - \\
\hline
\end{tabular}


Azimi et al. showed the same amount of phenolics for PKEO [17]. The findings of the present study revealed that ASEO possessed significantly higher phenolic content than PKEO. Indeed, EOs consist of secondary metabolites of plants, particularly the active lipophilic compounds, since solvents with a marked polarity can afford to extract higher amounts of phenolic compounds [40].

The PKEO and ASEO were tested for their inhibitory potential on AChE and BChE in vitro. As indicated in Fig. 1, PKEO reached an inhibition rate of $83.6 \%$ and $81.4 \%$ against $\mathrm{AChE}$ and $\mathrm{BChE}$, respectively. In this regard, ASEO had a lower anti-cholinesterase activity (65.4\% and 31.5\% for the inhibition of AChE and BChE) compared to PKEO. Therefore, both EOs had AChE and BChE inhibitory activities, with PKEO showing more strength. Noteworthy, our results showed that ASEO appeared to be a weak inhibitor of BChE; that is, the inhibition rate of BChE (31.5\%) was half of that achieved against AChE (65.4\%). Table 3 summarizes the in vivo activity of both enzymes in the presence of PKEO and ASEO. The inhibition rate of AChE at three different concentrations of PKEO was reported: Group 3 (PKEO 1\%): $38.5 \pm 0.1 \%$; Group 4 (PKEO 2\%): $56.4 \pm 0.2 \%$; Group 5 (PKEO 3\%): $62.2 \pm 0.3 \%$. Treatment of the rats with $1 \%, 2 \%$, and $3 \%$ of ASEO could improve $\mathrm{A} \beta$-induced increases in the AChE activity by $29.5 \pm 0.5 \%$, $36.4 \pm 0.2 \%$, and $40.2 \pm 0.2 \%$, respectively. In relation to Donepezil, PKEO 3\% and ASEO 1\% respectively expressed the highest $(62.2 \pm 0.3 \%)$ and lowest $(29.5 \pm 0.5 \%)$ rates of the AChE inhibition, which were statistically significant as compared with group $1(\mathrm{p}<0.05)$. Both EOs decreased the enzyme activity in a concentration-dependent manner. PKEO suppressed the AChE and BChE activity to the almost same degree, while on the contrary, ASEO showed more potential to inhibit the activity of AChE than BChE. In comparison with Donepezil, the significant difference in the BChE inhibition occurred as rats were treated with PKEO 1\%, ASEO 2\%, PKEO 3\%, and ASEO 3\% (p < 0.05).

There has some evidence confirming the anti-cholinesterase activity of AS or its family, Amaryllidaceae. Ncir et al. reported that AS extracts could successfully mitigate the brain and serum AChE activity in rats [16]. Borek [41] highlighted the potential of aged garlic extract in the reduction of the risk of dementia and AD through the brain protection against neurodegenerative conditions. Moreover, garlic is considered as an effective substance with great antimicrobial, cardiovascular, anti-inflammatory, anticancer, and immunomodulatory activities. However, it may cause some degree of toxicity at high doses [42]. The plant family is rich in alkaloid structures ascribed to their biogenesis from norbelladine, known as the common amino acid-derived precursor [43]. Galantamine, a natural product with considerable anti-cholinesterase properties, was originally extracted from snowdrop belonging to the Amaryllidaceae family [44]. Recently, it has been given an approval for clinical application and has become an effective therapeutic strategy to impede neurological degeneration in $\mathrm{AD}$ [11]. In another study by Okello et al., the cholinesterase inhibitory action of flower oil obtained from Narcissus poeticus L. was reported that belongs to the family Amaryllidaceae [12]. The GCMS analysis indicated the three major constituents, such as benzyl benzoate (19.0\%), phenylethyl alcohol (17.5\%), and benzyl alcohol (11.0\%). With $0.1 \mathrm{mg} / \mathrm{mL}$ concentration, an inhibition rate of $39 \%$ was achieved [12]. Despite the lack of galanthamine in AS, more recently, it has been shown that allicin has an ability to inhibit cholinesterase enzymes, and restore cognitive function and memory loss in AD [45]. Differently, some studies have highlighted the cholinesterase inhibitory activity of the plant species from the family Anacardiaceae [46, 47]. Hacıbekiroğlu et al. revealed that the ethanol and ethanol-water extracts of the P. terebinthus fruits and PK seeds could strongly inhibit the activity of AChE and BChE [19]. Of the family Anacardiaceae, Elufioye et al. reported that Spondias mombin with three main compounds, including botulin, campesterol and phytol, was active against AChE and BChE [46].

There was a strong correlation between the phenol content and the inhibition rate of AChE and BChE for ASEO and PKEO ( $\mathrm{r}>0.7, \mathrm{p}<0.05$ ) (Table 4). Ali Reza et al. confirmed the positive correlation between the total phenolics and inhibition of AChE and BChE by the methanolic extract of Elatostema papillosum rich in phenolic content [48]. Bone and Mills [49] highlighted that the polyphenols, tannins, and flavonoids as the major constituents of the biological material have unraveled remarkable cholinesterase inhibitory effects. This finding increases the importance of phytochemistry in the anti-cholinesterase activity of the plants. Moreover, this implies that the higher the phenolics the higher the enzyme inhibitory effects. The cholinesterase inhibitory activity of these plants has not previously studied elsewhere. Thus, this investigation showed data on the enzyme inhibition activity of PKEO and ASEO for the first time.

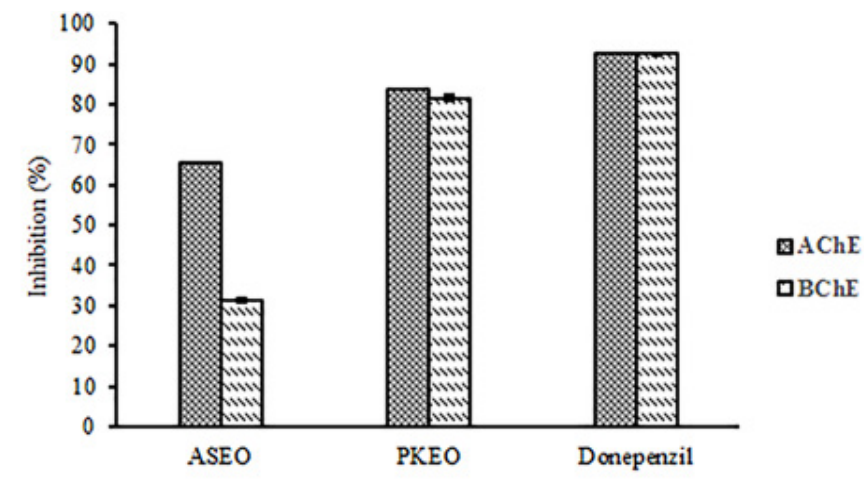

Figure 1 Cholinergic markers of PKEO and ASEO in vitro 
Table 3 Enzyme inhibitory activity of positive control (group 2) and different concentrations of PKEO and ASEO in vivo.

\begin{tabular}{ccc}
\hline Samples & AChE & BChE \\
& (Inhibition \%) & (Inhibition \%) \\
\hline PKEO 1\% & $38.5 \pm 0.1$ & $30.2 \pm 0.0^{*}$ \\
PKEO 2\% & $56.4 \pm 0.2$ & $51.2 \pm 0.1$ \\
PKEO 3\% & $62.2 \pm 0.3^{*}$ & $58.7 \pm 0.5^{*}$ \\
ASEO 1\% & $29.5 \pm 0.5^{*}$ & $\mathrm{ND}$ \\
ASEO 2\% & $36.4 \pm 0.2$ & $12.9 \pm 0.0^{*}$ \\
ASEO 3\% & $40.2 \pm 0.2$ & $28.1 \pm 0.4^{*}$ \\
Donepenzil & $45.5 \pm 0.6$ & $43.6 \pm 0.7$
\end{tabular}

$\overline{\text { Asterisks in each column indicating significant difference from group } 1(\mathrm{P}<0.05) .}$

Table 4 Correlation coefficients between the total phenolic contents and cholinesterase inhibitory activity of ASEO and PKEO

\begin{tabular}{ccc}
\hline Variables & \multicolumn{2}{c}{ Total phenol content } \\
\hline & PKEO & ASEO \\
\cline { 2 - 3 } AChE inhibitory activity & $0.978^{*}$ & $0.891^{*}$ \\
BChE inhibitory activity & $0.862^{*}$ & $0.762^{*}$ \\
\hline
\end{tabular}

Asterisks in each column indicating significance $\left(\mathrm{P}<0.05:{ }^{*}\right)$. 


\section{Conclusion}

In conclusion, the findings of the present study showed that the EO of Iranian $P$. khinjuk leaves and A. sativum cloves ameliorates amyloid $\beta$ induced disturbance in cholinesterase enzymes in rats using cholinergic markers. This anti-cholinesterase activity might be correlated with the phenolic content. Considering the antioxidant properties of both plant essential oils, for future studies, it will be of interest to investigate their effect on oxidative stress in $\mathrm{AD}$ as one of the major cause of neurotoxicity.

\section{Conflicts of Interest}

The authors declare that there is no conflict of interest concerning the publication of this article.

\section{References}

1. Sosa-Ortiz AL, Acosta-Castillo I, Prince MJ. Epidemiology of dementias and Alzheimer's disease. Archives of medical research. 2012;43(8):600-8.

2. Bartus RT, Dean Rr, Beer B, Lippa AS. The cholinergic hypothesis of geriatric memory dysfunction. Science. 1982;217(4558):408-14.

3. Du X, Wang X, Geng M. Alzheimer's disease hypothesis and related therapies. Translational Neurodegeneration. 2018;7:2.

4. Houghton PJ, Howes MJ. Natural products and derivatives affecting neurotransmission relevant to Alzheimer's and Parkinson's disease. Neurosignals. 2005;14(1-2):6-22.

5. Heinrich M, Lee Teoh H. Galanthamine from snowdrop-the development of a modern drug against Alzheimer's disease from local Caucasian knowledge. Journal of ethnopharmacology. 2004;92(2-3):147-62.

6. Grutzendler J, Morris JC. Cholinesterase inhibitors for Alzheimer's disease. Drugs. 2001;61(1):41-52.

7. Kumar A, Singh A, Ekavali. A review on Alzheimer's disease pathophysiology and its management: an update. Pharmacol Rep. 2015;67(2):195-203.

8. Essa MM, Vijayan RK, Castellano-Gonzalez G, Memon MA, Braidy N, Guillemin GJ. Neuroprotective effect of natural products against Alzheimer's disease. Neurochemical research. 2012;37(9):1829-42.

9. Ebrahimpour S, Fazeli M, Mehri S, Taherianfard M, Hosseinzadeh H. Boswellic Acid Improves Cognitive Function in a Rat Model Through Its Antioxidant Activity: - Neuroprotective effect of Boswellic acid. J Pharmacopuncture. 2017;20(1):10-7.

10. Edris AE. Pharmaceutical and therapeutic potentials of essential oils and their individual volatile constituents: a review. Phytotherapy research : PTR. 2007;21(4):308-23.

11. Ayaz M, Junaid M, Ullah F, Sadiq A, Khan MA, Ahmad W, et al. Comparative chemical profiling, cholinesterase inhibitions and anti-radicals properties of essential oils from Polygonum hydropiper L: A Preliminary anti- Alzheimer's study. Lipids in Health and Disease. 2015;14:141.

12. Okello E, Dimaki C, Howes M, Houghton P, Perry E. In vitro inhibition of human acetyl-and butyryl-cholinesterase by
Narcissus poeticus L. (Amaryllidaceae) flower absolute. Int J Essent Oil Ther. 2008;2:105-10.

13. Nishiyama N, Moriguchi T, Morihara N, Saito H. Ameliorative effect of S-allylcysteine, a major thioallyl constituent in aged garlic extract, on learning deficits in senescence-accelerated mice. The Journal of nutrition. 2001;131(3):1093S-5S.

14. Tasnim S, Haque PS, Bari MS, Hossain MM, Islam SMA, Shahriar M, et al. Allium sativum L. improves visual memory and attention in healthy human volunteers. Evidence-Based Complementary and Alternative Medicine. 2015;2015.

15. Chauhan NB. Anti-amyloidogenic effect of Allium sativum in Alzheimer's transgenic model Tg2576. Journal of herbal pharmacotherapy. 2003;3(1):95-107.

16. Ncir M, Saoudi M, Sellami H, Rahmouni F, Lahyani A, Makni Ayadi F, et al. In vitro and in vivo studies of Allium sativum extract against deltamethrin-induced oxidative stress in rats brain and kidney. Arch Physiol Biochem. 2018;124(3):207-17.

17. Azimi M, Sharifan A, Ghiasi Tarzi B. The Use of Pistacia khinjuk Essential Oil to Modulate Shelf-Life and Organoleptic Traits of Mechanically Deboned Chicken Meat. J Food Process Preserv; 2016.

18. Asha H. A Review: Natural Compounds as Anti-Alzheimer\&acute;s Disease Agents. Current Nutrition \& Food Science. 2017;13(4):247-54.

19. Hacıbekiroğlu Il, Yılmaz PK, Haşimi N, Kılınç E, Tolan V, Kolak U. In vitro biological activities and fatty acid profiles of Pistacia terebinthus fruits and Pistacia khinjuk seeds. Natural product research. 2015;29(5):444-6.

20. Rauf A, Patel S. Pistagremic acid as a broad spectrum natural inhibitor from Pistacia integerrima Stewart. Natural product research. 2017;31(4):367-8.

21. Aktumsek A, Zengin G, Guler GO, Cakmak YS, Duran A. Antioxidant potentials and anticholinesterase activities of methanolic and aqueous extracts of three endemic Centaurea L. species. Food and chemical toxicology : an international journal published for the British Industrial Biological Research Association. 2013;55:290-6. Epub 2013/01/30.

22. Kumar A, Prakash A, Dogra S. Centella asiatica attenuates D-galactose-induced cognitive impairment, oxidative and mitochondrial dysfunction in mice. International journal of Alzheimer's disease. 2011;2011:1-9.

23. Borek C. Antioxidant and cancer. Sci Med. 1997;4:51-62.

24. Gutteridge JM. Free radicals in disease processes: a compilation of cause and consequence. Free radical research communications. 1993;19(3):141-58. Epub 1993/01/01.

25. Moriguchi T, Saito H, Nishiyama N. Anti-ageing effect of aged garlic extract in the inbred brain atrophy mouse model. Clinical and experimental pharmacology \& physiology. 1997;24(3-4):235-42. Epub 1997/03/01.

26. Nishiyama N, Moriguchi T, Saito H. Beneficial effects of aged garlic extract on learning and memory impairment in the senescence-accelerated mouse. Experimental gerontology. 1997;32(1-2):149-60. Epub 1997/01/01.

27. Ghasemi Pirbalouti A, Aghaee K. Chemical composition of essential oil of Pistacia khinjuk stocks grown in Bakhtiari Zagross Mountains, Iran. Electronic Journal of Biology. 2011;7(4):67-9. 
28. Taran M, Sharifi M, Azizi E, Khanahmadi M. Antimicrobial activity of the leaves of Pistacia khinjuk. Journal of Medicinal Plants. 2010;1(33):81-5.

29. Inglis F. The tolerability and safety of cholinesterase inhibitors in the treatment of dementia. International journal of clinical practice Supplement. 2002(127):45-63.

30. Jann MW, Shirley KL, Small GW. Clinical pharmacokinetics and pharmacodynamics of cholinesterase inhibitors. Clinical pharmacokinetics. 2002;41(10):719-39.

31. Abolghasemi A, Shojaaddini M, Tajabadipour A, Sefidkon F. Composition of Pistacia khinjuk (Anacardiaceae) Leaf Essential Oil and its Insecticidal Activity on Common Pistachio Psyllid, Agonoscena pistaciae (Hem., Psylloidea). Journal of Essential Oil Bearing Plants. 2018;21(3):796-802.

32. Taran M, Sharifi M, Azizi E, Khanahmadi M. Antimicrobial activity of the leaves of Pistacia khinjuk. J Medicin Plant 2010;1(33):81-5.

33. De Pooter H, Schamp N, Aboutabl E, El Tohamy S, Doss S. Essential oils from the leaves of three Pistacia species grown in Egypt. Flavour and Fragrance journal. 1991;6(3):229-32.

34. Rahnama M, Najimi M, Ali S. Antibacterial effects of Myristica fragrans, Zataria multiflora Boiss, Syzygium aromaticum, and Zingiber officinale Rosci essential oils, alone and in combination with nisin on Listeria monocytogenes. Comp Clin Pathol. 2012;21(6):1313-6.

35. Khadri S, Boutefnouchet N, Dekhil M. Antibacterial activity evaluation of Allium sativum essential oil compared to different Pseudomonas aeruginosa strains in Eastern Algeria. Scientific Study \& Research. 2010;11(4):421-8.

36. Lawrence R, Lawrence K. Antioxidant activity of garlic essential oil (Allium sativum) grown in north Indian plains. Asian Pac J Trop Biomed. 2011;1(Suppl 1):S51-S54.

37. Mnayer D, Fabiano-Tixier AS, Petitcolas E, Hamieh T, Nehme N, Ferrant C, et al. Chemical composition, antibacterial and antioxidant activities of six essentials oils from the Alliaceae family. Molecules (Basel, Switzerland). 2014;19(12):20034-53. Epub 2014/12/04.

38. Casella S, Leonardi M, Melai B, Fratini F, Pistelli L. The role of diallyl sulfides and dipropyl sulfides in the in vitro antimicrobial activity of the essential oil of garlic, Allium sativum L., and leek, Allium porrum L. Phytotherapy Research. 2013;27(3):380-3.

39. Corzo-Martínez M, Corzo N, Villamiel M. Biological properties of onions and garlic. Trends in food science \& technology. 2007;18(12):609-25.

40. Sultana B, Anwar F, Przybylski R. Antioxidant activity of phenolic components present in barks of Azadirachta indica, Terminalia arjuna, Acacia nilotica, and Eugenia jambolana Lam. trees. Food Chemistry. 2007;104(3):1106-14.

41. Borek C. Garlic reduces dementia and heart-disease risk. J Nutr. 2006;136(3):810S-2S.

42. Mikaili P, Maadirad S, Moloudizargari M, Aghajanshakeri S, Sarahroodi S. Therapeutic uses and pharmacological properties of garlic, shallot, and their biologically active compounds. Iranian journal of basic medical sciences. 2013;16(10):1031-48. Epub 2014/01/01.

43. Cortes N, Posada-Duque RA, Alvarez R, Alzate F, Berkov S, Cardona-Gómez GP, et al. Neuroprotective activity and acetylcholinesterase inhibition of five Amaryllidaceae species: A comparative study. Life sciences. 2015;122:42-50.

44. Heinrich M, Teoh HL. Galanthamine from snowdrop-the development of a modern drug against Alzheimer's disease from local Caucasian knowledge. Journal of ethnopharmacology. 2004;92(2-3):147-62.

45. Kumar S. Dual inhibition of acetylcholinesterase and butyrylcholinesterase enzymes by allicin. Indian journal of pharmacology. 2015;47(4):444-6.

46. Elufioye TO, Obuotor EM, Agbedahunsi JM, Adesanya SA. Anticholinesterase constituents from the leaves of Spondias mombin L. (Anacardiaceae). Biologics : Targets \& Therapy. 2017;11:107-14.

47. Moyo M, Ndhlala AR, Finnie JF, Van Staden J. Phenolic composition, antioxidant and acetylcholinesterase inhibitory activities of Sclerocarya birrea and Harpephyllum caffrum (Anacardiaceae) extracts. Food Chemistry. 2010;123(1):69-76.

48. Ali Reza ASM, Hossain MS, Akhter S, Rahman MR, Nasrin MS, Uddin MJ, et al. In vitro antioxidant and cholinesterase inhibitory activities of Elatostema papillosum leaves and correlation with their phytochemical profiles: a study relevant to the treatment of Alzheimer's disease. BMC complementary and alternative medicine. 2018;18:123.

49. Bone K, Mills S. Principles and practice of phytotherapy: modern herbal medicine. London, UK: Elsevier Health Sciences; 2013. 